\title{
Fuzzy rule-based model to optimize outflow in single reservoir operation
}

\author{
Edy Anto Soentoro ${ }^{1, *}$ and Nina Pebriana ${ }^{2}$ \\ ${ }^{1}$ Water Resources Engineering Research Group, Faculty of Civil and Environmental Engineering, Institut Teknologi Bandung, \\ Bandung, Indonesia \\ ${ }^{2}$ Department of Civil Engineering, Faculty of Civil Engineering and Planning, University of Surakarta, Surakarta, Indonesia
}

\begin{abstract}
Reservoir operations, especially those which regulate the outflow (release) volume, are crucial for the fulfillment of the purpose to build the reservoir. To get the best results, outflow (release) discharges need to be optimized to meet the objectives of the reservoir operation. A fuzzy rule-based model was used in this study because it can deal with uncertainty constraints and objects without clear or well-defined boundaries. The objective of this study is to determine the maximum total release volume based on water availability (i.e., a monthly release is equal to or more than monthly demand). The case study is located at Darma reservoir. A fuzzy rule-based model was used to optimize the monthly release volume, and the result was compared with that of NLP and the demand. The Sugeno fuzzy method was used to generate fuzzy rules from a given input-output data set that consisted of demand, inflow, storage, and release. The results of this study showed that the release of Sugeno method and the demand have the same basic pattern, in which the release fulfill the demand. The overall result showed that the fuzzy rule-based model with Sugeno method can be used for optimization based on real-life experiences from experts that are used to working in the field.
\end{abstract}

\section{Introduction}

Water is the most important and vulnerable natural resource, so it needs to be utilized as much as possible for mutual welfare, to be protected, developed, integrated used and controlled. The reservoir is built with various objectives including agricultural, hydro-electric generation, fish farming, sports, flood control or for tourism. Reservoir operations, especially those that regulate the outflow (release volume) of water, manage the fulfillment of the reservoir's objectives. Release is an outflow discharge that is regulated by reservoir operation through a sluice gate, while outflow is the total discharge coming out of the reservoir including spill discharge during floods.

To get the best results from the objectives of the reservoir operation, a release discharge is regulated by optimization. There are many optimization methods such as Linear Programming (LP), Non-Linear Programming (NLP), Genetic Algorithm, Fuzzy rule-based, and Neural Network methods.

The fuzzy rule-based method was pioneered by Zadeh [1] who laid out the base of fuzzy logic (fuzzy set theory) from mathematics. Zadeh had observed that conventional computer logic could not manipulate data that represented subjective or imprecise ideas, so he created fuzzy logic to allow computers to determine the distinctions among data with shades of gray, like the process of human reasoning. Ten years later, Mamdani [2] developed the fuzzy inference technique that called Mamdani method. The Mamdani method was widely accepted for capturing expert knowledge and more human-like manner. However, the method required a substantial computational burden. Later, Sugeno [3, 4] proposed his fuzzy inference technique that simpler than that of Mamdani. The Sugeno method is computationally effective and works well with optimization and adaptive techniques, which makes it very attractive in adaptive problems, particularly for nonlinear systems

Bardossy [5] said that fuzzy rule-based modeling can deal with uncertain constraints (e.g., probability theory and statistics), and objects without clear boundaries or well defined. The fuzzy rule-based approach can provide a more promising alternative with the presence of stochastic hydrological variables for reservoir operation modeling.

Fontane et. al. [6] had applied fuzzy rule-based approach for imprecise objectives of reservoir operation, such us for water supply demand, flood control space, and kayaking as in stream flow. Nayak et. al. [7] applied fuzzy logic for model identification based on cluster estimation for reservoir inflow forecasting. The operating conditions

\footnotetext{
*Corresponding author: edyas209@gmail.com
} 
of the reservoir so far are often regarded as deterministic, meaning that the data affecting the operation of reservoirs such as inflow data and data on water requirements have been determined or known as certain data. The actual inflow data and water demand data, however, are uncertain when it is decided to release the release discharge. Application of the Sugeno inference method in other field of studies are by Cavallaro [8] who applied the Sugeno method for developing a sustainability index of biomass, and Mehran [9] who used fuzzy model for process control in industrial automation based on Sugeno fuzzy inference. The objective of this study is to determine the maximum total release volume based on water availability (i.e., monthly release is equal or more than monthly demand). The case-study location is at Darma reservoir. As a comparison, the result of fuzzy rule-based model was compared with that of the NLP model and the demand pattern, so that it can represent the reliability of the two methods. And from both it can be recommended the best operating pattern guideline that produces optimum release in order to maximize the water use in the reservoir.

In reservoir operation by NLP method with the aim of maximizing the annual water release, the calculation uses Solver in Microsoft Excel. The results obtained are in the form of releases and some other information such as active storage and elevation of active reservoirs.

\section{Fuzzy Rule-Based method}

A fuzzy model uses fuzzy rules, which are linguistic IF THEN statements involving fuzzy sets, fuzzy logic, and fuzzy inference. Fuzzy rules play a key role in representing expert control/modeling knowledge and experience and in linking the input variables of fuzzy models to output variables. One of types of fuzzy rules are Sugeno (or Takagi Sugeno) method. The Sugeno fuzzy method was proposed to develop a systematic approach to generate fuzzy rules from a given input-output data set. A typical fuzzy rule in a Sugeno fuzzy model has the form:

$$
\text { if } x \text { is } A \text { and } y \text { is } B \text { then } z=f(x, y)
$$

where $\mathrm{A}$ and $\mathrm{B}$ are fuzzy sets in the antecedent, while $\mathrm{z}=$ $f(x, y)$ is a crisp function in the consequent. Usually $f(x$, $\mathrm{y}$ ) is a polynomial in the input variables $\mathrm{x}$ and $\mathrm{y}$, but it can be any function as long as it can appropriately describe the output of the model within the fuzzy region specified by the antecedent of the rule.

When $f(x, y)$ is a first-order polynomial, the resulting fuzzy inference system is called a first-order Sugeno fuzzy model. When $f$ is a constant, we then have a zero-order Sugeno fuzzy model, in which each rule's consequent is specified by an MF of a step function center at the constant. The output of a zero-order Sugeno model is a smooth function of its input variables as long as the neighboring MFs in the antecedent have enough overlap.

Without the time-consuming and mathematically intractable defuzzification operation, the Sugeno fuzzy model is by far the most popular candidate for sampledata-based fuzzy modelling.

\subsection{Fuzzy Sugeno Order-Zero model}

The general form of the SUGENO Order-Zero fuzzy model is:

$\mathrm{IF}(\mathrm{x} 1$ is $\mathrm{A} 1) \cdot(\mathrm{x} 2$ is $\mathrm{A} 2) \bullet(\mathrm{x} 3$ is $\mathrm{A} 3) \cdot \ldots . .(\mathrm{xn}$ is $\mathrm{An})$

$$
\text { THEN } z=\mathrm{k}
$$

with $\mathrm{Ai}$ is the fuzzy set of $\mathrm{i}$ as an antecedent, therefore $\mathrm{k}$ is a constant (consistent).

\subsection{Fuzzy Sugeno Order-One model}

The general form of the fuzzy Sugeno Order-One model is:

$$
\begin{aligned}
& \mathrm{IF}(\mathrm{x} 1 \text { is } \mathrm{A} 1) \cdot \ldots \ldots \cdot(\mathrm{xN} \text { is } \mathrm{AN}) \mathrm{THEN} \mathrm{z}=\mathrm{p} 1 * \mathrm{x} 1 \\
& +\ldots \ldots . .+\mathrm{pN} * \mathrm{xN}+\mathrm{q}
\end{aligned}
$$

with $\mathrm{Ai}$ is a fuzzy set $\mathrm{i}$ as an antecedent, and pi is a (firm) constant $\mathrm{i}$ and $\mathrm{q}$ is also a consequent constant. For the composition of the rules with the SUGENO method, deffuzification is done by finding the average. In modeling reservoir operations with fuzzy rule-based, the steps are described in the figure below:

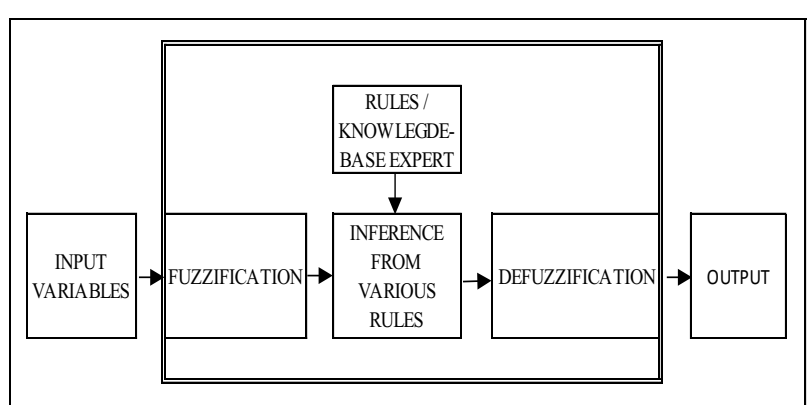

Fig. 1. Diagram proses of the study

Input variables have crisp value such as inflows, demands and storage volumes. The fuzzification is to convert the input variables into fuzzy set system. Then the inference based on rules that applied on the system. The applied rules come from judgement using knowledge base expert system. Finally, defuzzification prosses and the output.

\section{Study case and location}

The case study was carried out at Darma Reservoir, located at the upper part of the Cisanggarung river. Geographically located between $6^{\circ} 66^{\prime} 47^{\prime L S}$ to $7^{\circ} 3^{\prime} 40^{\prime \prime}$ LS and $108^{\circ} 22^{\prime} 54$ "BT up to $108^{\circ} 25^{\prime} 28^{\prime \prime}$ BT. This reservoir covers area of 425 hectares and it has maximum storage of $40,200,000 \mathrm{~m} 3$ water with the effective storage is $38,620,000 \mathrm{~m} 3$. 


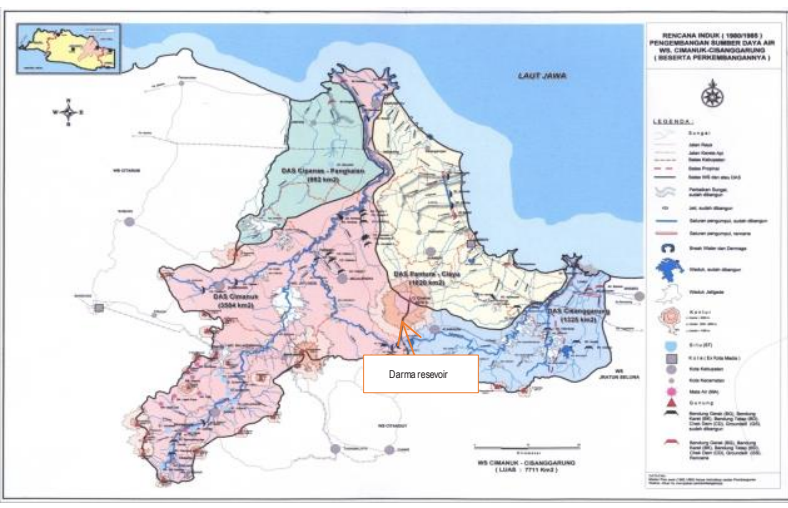

Fig. 2. Location of Darma reservoir

(Source : BBWS Cimanuk - Cisanggarung)

Darma Reservoir was built by blocking the flow of the Cisanggarung river and some of its tributaries, such as Cilame river, Cikalapa, Cilandak, Cimuncang, and Cinangka rivers, as well as several springs such as Cibuntu, Citambang and Balong Beunteur. The total area of the watershed is approximately $23.50 \mathrm{~km} 2$. The Darma reservoir began operations in 1962 with the area served area is 19,337 ha of irrigated area, covering 6,620 ha in Kuningan regency and 13,117 ha in Cirebon Regency. In addition, the Darma reservoir also serves 80 liters/sec of raw water supply of PDAM for the Kuningan regency.

Table 1. Technical data of Darma reservoir

\begin{tabular}{|l|c|}
\hline \multicolumn{1}{|c|}{ Items } & Value \\
\hline Maximum water elevation & $+713.00 \mathrm{~m} \mathrm{MSL}$ \\
\hline Minimum water elevation & $+702.60 \mathrm{~m} \mathrm{MSL}$ \\
\hline Reservoir based elevation & $+694.00 \mathrm{~m} \mathrm{MSL}$ \\
\hline Maximum storage capacity & $38,500,000 \mathrm{~m} 3$ \\
\hline Effective storage capacity & $36,500,000 \mathrm{~m} 3$ \\
\hline Maximum surface water area & $425 \mathrm{ha}$ \\
\hline Catchment area & $480 \mathrm{ha}$ \\
\hline Raw water demand for PDAM & $60 \mathrm{liter} / \mathrm{sec}$ \\
\hline
\end{tabular}

(Source: BBWS Cimanuk - Cisanggarung)

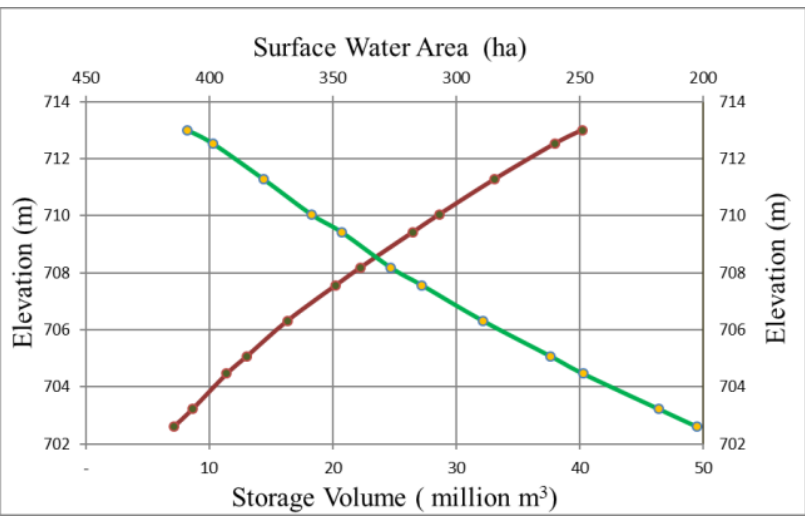

Fig. 3. Relationship curve between elevation, storage volume, and surface water area

(Source: BBWS Cimanuk - Cisanggarung)

Based on data from the Cimanuk - Cisanggarung Water Resources Management Office (PSDA), the present storage capacity of the Darma reservoir is about \pm 30 million $\mathrm{m} 3$, it decreased from \pm 40 million $\mathrm{m} 3$. The decrease of the storage capacity is caused by several factors such as sedimentation in reservoirs, lack of watershed conservation around the reservoir the leakage (seepage) that was occurred at Darma dam or reservoir. This situation is considered necessary to study on an arrangement of water released of Darma reservoir to meet the needs of the water as efficiently as possible, as to obtain great benefits in it. The applied operating release pattern is expected to provide input for decision makers and can be the most optimal solution to meet water needs.

Table 2. The relationship between elevation and leakage

\begin{tabular}{|c|c|c|}
\hline No & Elevation $(\mathrm{m})$ & Leakage $(\mathrm{m} 3 / \mathrm{s})$ \\
\hline 1 & 703.7727 & 0.005000 \\
\hline 2 & 703.9720 & 0.005000 \\
\hline 3 & 704.3900 & 0.005067 \\
\hline 4 & 704.3106 & 0.005438 \\
\hline 5 & 704.9244 & 0.006000 \\
\hline 6 & 705.4107 & 0.006133 \\
\hline 7 & 706.7927 & 0.009200 \\
\hline 8 & 708.0267 & 0.013600 \\
\hline 9 & 709.0419 & 0.017125 \\
\hline 10 & 710.0167 & 0.023733 \\
\hline 11 & 710.1387 & 0.025867 \\
\hline 12 & 710.9931 & 0.032250 \\
\hline 13 & 711.1706 & 0.036250 \\
\hline 14 & 711.6760 & 0.045133 \\
\hline 15 & 711.7667 & 0.049267 \\
\hline 16 & 712.4700 & 0.056400 \\
\hline 17 & 712.5988 & 0.059625 \\
\hline 18 & 712.6827 & 0.060000 \\
\hline
\end{tabular}

(Source: BBWS Cimanuk - Cisanggarung)

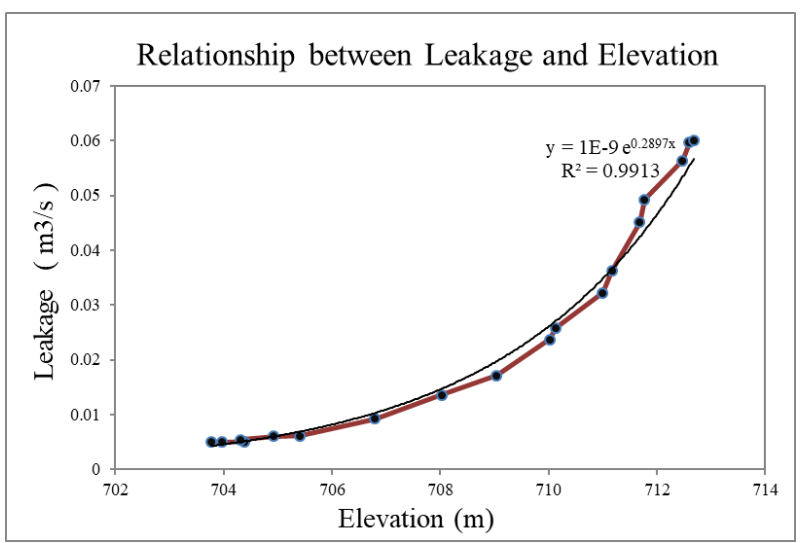

Fig. 4. The relationship curve between elevation $(\mathrm{m})$ and leakage $\left(\mathrm{m}^{3} / \mathrm{s}\right)$

In addition to data above, the study used field data of historic inflow, outflow, active storage and demand of Darma reservoir from 2002 to 2012. The main objective of the Darma reservoir is to fulfill the needs of irrigation and raw water supply for PDAM. For further data analysis, inflow, storage and demand data is divided by 11 to find the average annual data. The evaporation data is 
calculated in each month from the existing daily data, while the leakage data is calculated through the equations obtained from the graph of the relationship of elevation and leakage.

Irrigation and raw water supply demand used in this study are the average needs for 11 years from 2002 to 2012, based on data from BBWS Cimanuk-Cisanggarung.

Tabel 3. Data of average water demand, inflow, storage, evaporation, seepage/leakage, and actual release

\begin{tabular}{|c|c|c|c|c|c|c|}
\hline \multirow{2}{*}{ Month } & Demand & Inflow & Storage & Evaporation & Leakage & Release \\
\hline & $10^{6} \mathrm{~m}^{3}$ & $10^{6} \mathrm{~m}^{3}$ & $10^{6} \mathrm{~m}^{3}$ & $10^{6} \mathrm{~m}^{3}$ & $10^{6} \mathrm{~m}^{3}$ & $10^{6} \mathrm{~m}^{3}$ \\
\hline Jan & 7.281 & 24.894 & 26.943 & 4.28544 & 0.021481 & 13.645 \\
\hline $\mathrm{Feb}$ & & 5.642 & & & 1426 & \\
\hline Mar & & 05 & & & & \\
\hline Apr & 31. & 89.073 & & & 240 & 506 \\
\hline May & & & & & & \\
\hline Jun & 108 & 128.342 & & & 106 & 125.010 \\
\hline Jul & 166. & 170.048 & & & 017 & .506 \\
\hline Aug & & 188.039 & & & 784 & .176 \\
\hline Sep & & 198.621 & & & 0.009429 & 197.821 \\
\hline Oct & 103.690 & & & & & 111.857 \\
\hline Nov & & & & & 0.006415 & 30.310 \\
\hline Dec & 17.237 & 31.856 & 19.739 & 5.35680 & 0.009341 & 23.523 \\
\hline
\end{tabular}

\section{Formulation of the Fuzzy Rule-Based model}

Fuzzy variables consisting of inflow, storage, demand, and actual release data obtained from the average 11 years. For the operating pattern with fuzzy logic method, the stages consist of:

- Formation of a fuzzy function

Each fuzzy variable is formed into a fuzzy set which is a group that represents the conditions of each variable.

- Membership function of fuzzy variables

For each fuzzy variable the membership function approach consists of: demand variables using linear and upward representation curves, while for inflow, storage and release using triangular and shoulder curves, the selection of curves is only to show the simplicity of the membership function of each fuzzy variable

- Function of Implications and their applications. The membership value as a result of 2 set operations is called $\alpha$-predicate, the general form of fuzzy rules in the implication function of fuzzy variables is;

IF is called an antecedent

THEN is called a consequent

AND called a fuzzy operator

In this study the method used is fuzzy inference with the Sugeno method, so the consequence of the rules in the form of IF-THEN is no longer a fuzzy set but rather a constant, while the defuzzification of the Sugeno method is done by finding the average value.
Table 4. Fuzzy set

\begin{tabular}{|c|c|c|}
\hline Fuzzy variable & \# of set & Name of Fuzzy set \\
\hline Demand & 2 & Up and Down \\
\hline Inflow & 5 & $\begin{array}{c}\text { Very wet, Wet, Normal, } \\
\text { Dry, and Very dry }\end{array}$ \\
\hline Storage & 4 & $\begin{array}{c}\text { Very high, High, Medium, } \\
\text { and Low }\end{array}$ \\
\hline Release & 5 & $\begin{array}{c}\text { A lot of, Many, Medium, } \\
\text { Few, and Very few }\end{array}$ \\
\hline
\end{tabular}

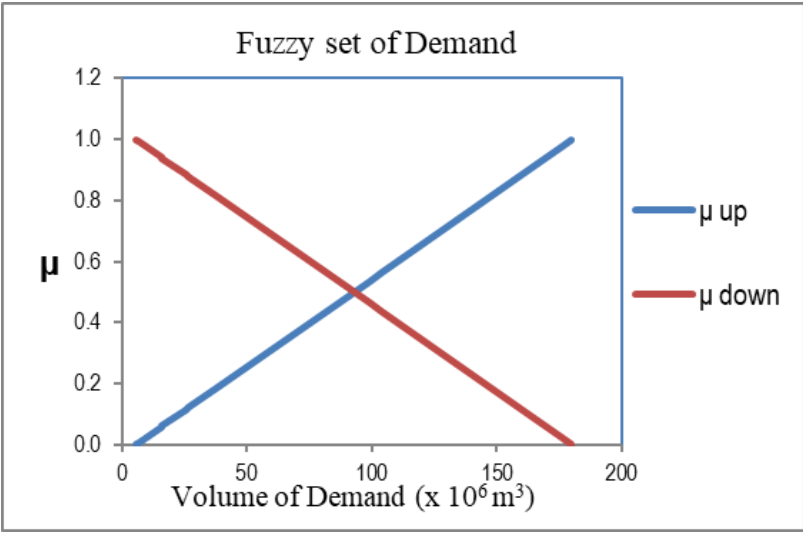

Fig. 5. Fuzzy set of demand

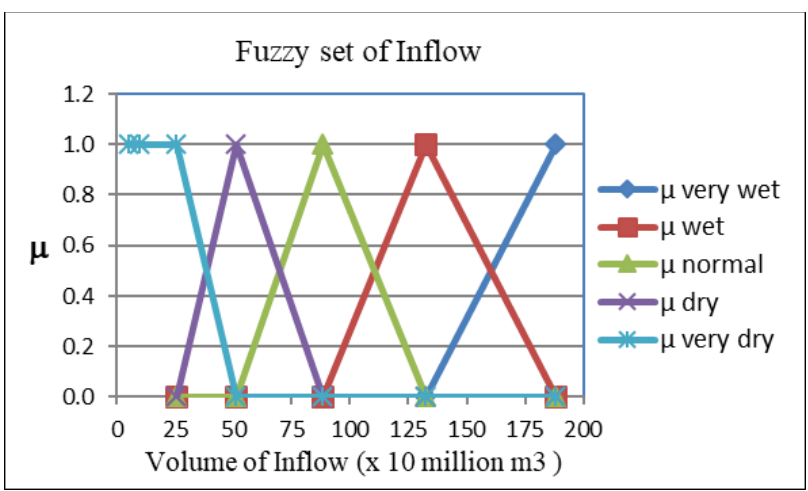

Fig. 6. Fuzzy set of inflow

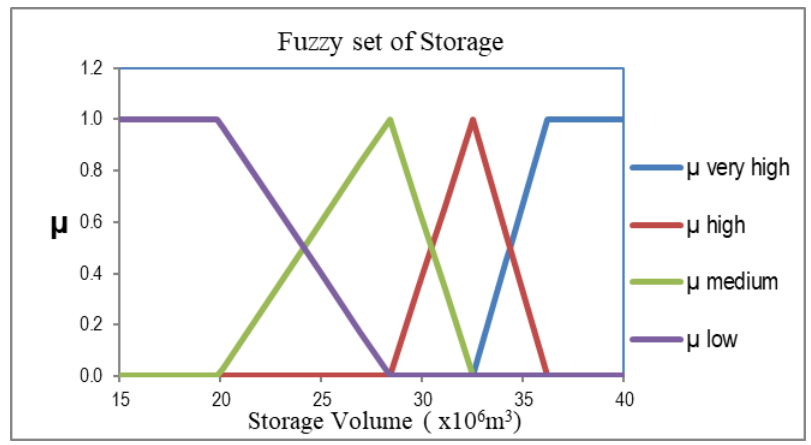

Fig. 7. Fuzzy set of storage 


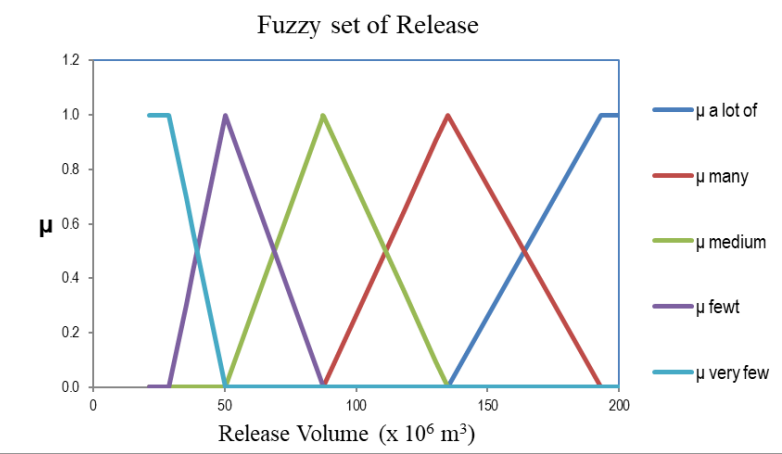

Fig. 8. Fuzzy set of release

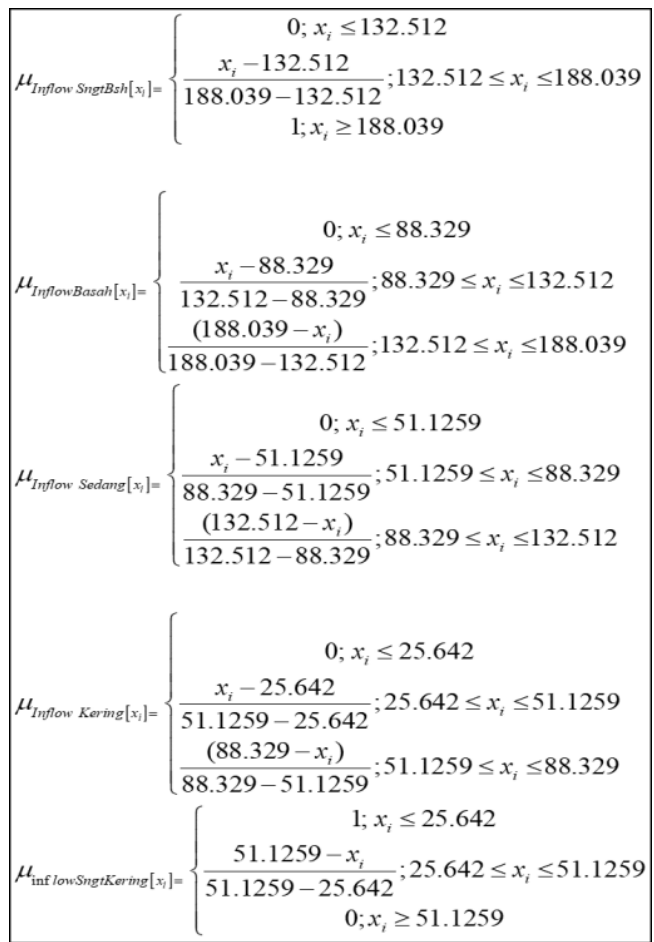

Fig. 9. Example of fuzzy membership function of inflow

Table 5. Fuzzy Rule with Sugeno method

\begin{tabular}{|c|c|}
\hline Rule \# & Fuzzy knowledge base Rules \\
\hline [R1]: & $\begin{array}{l}\text { IF Demand DOWN And Storage LOW And Inflow VERY DRY } \\
\text { THEN Release = INFLOW; }\end{array}$ \\
\hline$[\mathrm{R} 2]:$ & $\begin{array}{l}\text { IF Demand DOWN And Storage High And Inflow VERY DRY } \\
\text { THEN Release = INFLOW; }\end{array}$ \\
\hline$[\mathrm{R} 3]$ : & $\begin{array}{l}\text { IF Demand DOWN And Storage VERY HIGH And Inflow DRY } \\
\text { THEN Release = DEMAND; }\end{array}$ \\
\hline [R4]: & $\begin{array}{l}\text { IF Demand DOWN And Storage VERY HIGH And Inflow WET } \\
\text { THEN Release = DEMAND; }\end{array}$ \\
\hline [R5]: & $\begin{array}{l}\text { IF Demand DOWN And Storage VERY HIGH And Inflow NORMAL } \\
\text { THEN Release = INFLOW; }\end{array}$ \\
\hline [R6] : & $\begin{array}{l}\text { IF Demand UP And Storage HIGH And Inflow WET } \\
\text { THEN Release }=1.05^{*} \text { DEMAND }\end{array}$ \\
\hline [R7] : & $\begin{array}{l}\text { IF Demand UP And Storage HIGH And Inflow VERY WET } \\
\text { THEN Release = } 1.2 * \text { DEMAND; }\end{array}$ \\
\hline [R8]: & $\begin{array}{l}\text { IF Demand UP And Storage MEDIUM And Inflow VERY WET } \\
\text { THEN Release = DEMAND; }\end{array}$ \\
\hline [R9]: & $\begin{array}{l}\text { IF Demand UP And Storage LOW And Inflow VERY WET } \\
\text { THEN Release = INFLOW; }\end{array}$ \\
\hline [R10]: & $\begin{array}{l}\text { IF Demand UP And Storage LOW And Inflow WET } \\
\text { THEN Release = INFLOW; }\end{array}$ \\
\hline [R11]: & $\begin{array}{l}\text { IF Demand DOWN And Storage LOW And Inflow DRY } \\
\text { THEN Release = INFLOW; }\end{array}$ \\
\hline [R12]: & $\begin{array}{l}\text { IF Demand DOWN And Storage LOW And Inflow VERY DRY } \\
\text { THEN Release }=0.8 * \text { INFLOW; }\end{array}$ \\
\hline
\end{tabular}

\section{Non-Linear Programming (NLP) model}

Non-Linear Programming optimization model for reservoir operation is to maximize annual water supply (release) that can be written as follow:

Obj Func : Max Water supply $=\sum \mathrm{R}_{\mathrm{t}}$

Subject to:

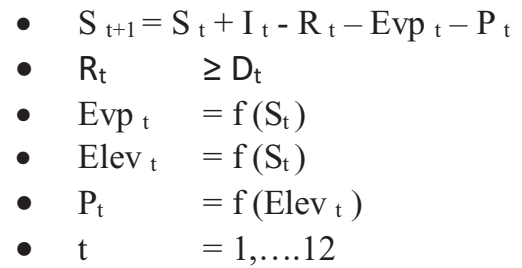

in which :

$\mathrm{S}_{\mathrm{t}+1}=$ storage volume at the end of the stage

$\mathrm{S}_{\mathrm{t}}=$ storage volume at the beginning of the stage

$\mathrm{R}_{\mathrm{t}}=$ release volume at the beginning of the stage

$\mathrm{E}_{\mathrm{t}}=$ evaporation at the beginning of the stage

Elev ${ }_{\mathrm{t}}=$ elevation at the beginning of the stage

$\mathrm{P}_{\mathrm{t}}=$ leakage that occurs at the beginning of the stage, obtained from the value of storage and elevation

\section{Result and analysis}

Sugeno inference system on fuzzy rule-based techniques is used to optimize release of Darma reservoir operation, and the result is compared with that from Non-Linear Programming (NLP). The result is presented in the figure 10.

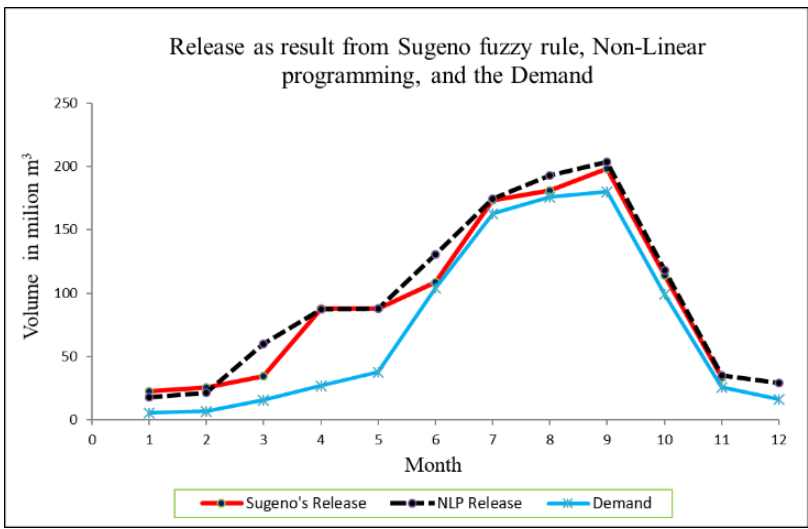

Fig. 10. Release as result from Sugeno fuzzy rule, Non- linear programming, and the Demand

Based on the curve in Figure 10 above, releases with Sugeno \& NLP methods and the demand are above the demand for each month, meaning that the release of both methods can meet the water demand. The results of the two methods above and the demand data show a similar pattern, and it shows the same characteristics in the calculation results. However, the result of the Sugeno method seems to be closer to demand than with that of the NLP method, so it is better because more water can be saved. 


\section{Conclusion}

Release results from the Sugeno and NLP methods, and the demand showed similar patterns, and both methods can fulfill the water demand for each month. Based on the release curve, Sugeno fuzzy method looks more optimal because of the difference between total release by Sugeno and total demand, it is smaller than that by NLP. The overall result showed that the fuzzy rule-based model with Sugeno method can be used for optimization based on real-life experiences from experts that are used to working in the field.

\section{References}

1. L.A. Zadeh, Fuzzy Set, the University of California at Berkeley publication, (1965), (source: History of Fuzzy Logic, Computer World)

2. E.H. Mamdani, and S. Assilian, An experiment in linguistic synthesis with a fuzzy logic controller, International Journal of Man-Machine Studies, 7 (1):1-13, (1975)

3. M. Sugeno, and G. Kang, "Structure identification of fuzzy model", Fuzzy Sets and Systems, Vol. 28, no. 1, pp. 15-33, (1988)

4. T. Takagi, and M. Sugeno, "Fuzzy identification of systems and its applications to modeling and control", IEEE Transactions on systems, man, and cybernetics, Vol. 15, no. 1, pp. 116-132, (1985)

5. A. Bardossy, and L. Duckstein, Fuzzy Rule-based Modeling with Application to Geophysical, Biological, and Engineering System, CRC Press, Boca Raton (1995)

6. D.G. Fontane, T.K. Gates, and E. Moncada, Planning reservoir operation with imprecise objectives, Journal of Water Resources Planning and Management, Vol. 123, No.3, (1997)

7. P.C. Nayak, and K. P. Sudheer, Fuzzy model identification based on cluster estimation for reservoir inflow forecasting, Journal of Hydrological Process, 22, 827-841, Published online in Wiley Inter Science, (2008)

8. F. Cavallaro, A Takagi-Sugeno Fuzzy Inference System for Developing a Sustainability Index of Biomass, Sustainability-Open Access Journal, 2015, vol. 7, page:12359-12371, (2015)

9. K. Mehran, "Takagi-Sugeno Fuzzy Modeling for Process Control, Industrial Automation", Robotics and Artificial Intelligence (EEE8005), School of Electrical, Electronic and Computer Engineering, Newcastle University, (2008)

10. C. ReVelle, Optimizing Reservoir Resources: Including New Model for Reservoir Realibility, John Wiley \& Sons, Inc., NewYork, (1999) 